\title{
Are existing soils data meeting the needs of stakeholders in Europe? An analysis of practical use from policy to field
}

\author{
Campbell $^{1,2}$, G. A., Lilly ${ }^{1}$, A., Corstanje ${ }^{2}$, R., Mayr², T.R., and Black ${ }^{1}$, H.I.J. \\ 1 The James Hutton Institute, Craigiebuckler, Aberdeen, AB15 8QH. \\ ${ }^{2}$ Cranfield University, College Road, Cranfield, Bedford, MK43 OAL. \\ E-mail address: Grant.Campbell@hutton.ac.uk
}

\section{Abstract}

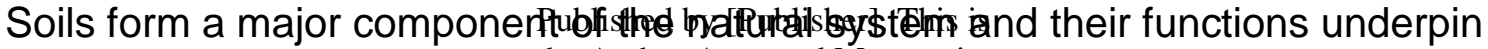
the Author Accepted Manuscript

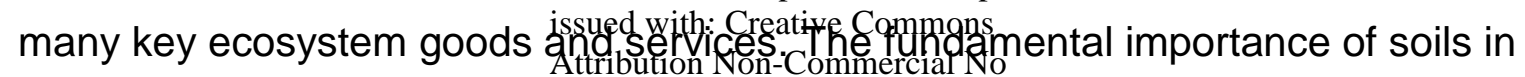
Derivatives License

the environment means that marnydiffekent.(0)rganisations and stakeholders make The final published version (version

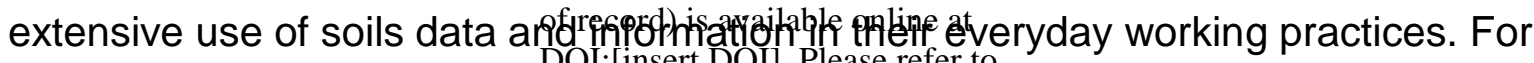
DOI:[insert DOI]. Please refer to

many reasons, stakeholders are not always aware that they are reliant upon soil data

and information to support their activities. Various reviews of stakeholder needs and

how soil information could be improved have been carried out in recent years.

However, to date, there has been little consideration of user needs from a non-expert perspective. The aim of this study was to explore the use of explicit and hidden soil information in different organisations across Europe and gain a better understanding of improvements needed in soil data and information to assist in practical use by non-expert stakeholders. An on-line questionnaire was used to investigate different uses of soils data and information with 310 responses obtained from 77 organisations across Europe. Results illustrate the widespread use of soil data and information across diverse organisations within Europe, particularly spatial products 
and soil functional assessments and tools. A wide range of improvements were expressed with a prevalence for finer scale resolution, trends over time, future scenarios, improved accuracy, non-technical supporting information and better capacity to use GIS. An underlying message is that existing legacy soils data need to be supplemented by new up-to-date data to meet stakeholder needs and information gaps.

Keywords

Soils, soil functions, questionnaire, stakeholders, non-expert, data, improvements

\section{Highlights}

- The fundamental importance of soils in the environment means that decision makers make extensive use of soils data and information

- A questionnaire was constructed to investigate stakeholders' use of soil assessments and tools as well as looking at desired improvements on information they currently use.

- $\quad$ The questionnaire yielded 310 responses from 77 organisations across Europe.

- Stakeholders in agriculture and research are more likely to request improvements in finer scale resolution for soil mapping applications.

- Stakeholders communicated the fundamental importance of contemporary data and spatial soils information for wider scale applications and contemporary data and their end user needs. 


\section{Introduction}

Soils form a major component of our natural environment on Earth, performing an array of essential functions that underpin key ecosystem goods and services which we rely on (Costanza et al. 1997; Smith et al. 2015). The significance of soils within the environment has meant that stakeholders have to use a wide variety of soils data and information in their decision making.

The concept of soil functions was first conceived during the early 1950 s and has since been widely adopted in national and regional policy (Blum, 2005). From the mid-1900s onwards, soils functional aspects have been incorporated into assessment tools such as maps and models that assist decision makers across a wide range of soil-related issues from land use, cropping practises, protection of water bodies, and restoration of habitats to climate regulation. For instance, many early assessments around agricultural productivity, such as the Land Capability for Scotland (Bibby et al, 1988) and laterally, the CAPRI model (Britz and Witzke, 2014), are based on soil maps. However, functional assessments have since extended across many other issues such as groundwater vulnerability (Environment Agency, 2013; Harter and Walker, 2001).

When exploring what needs to be improved in terms of soils data and information, we need to understand the contemporary needs of stakeholders particularly where soils data and information may be implicit or part of an underlying model or assessment tool. There are various reviews of stakeholder needs and how these levels of information could be improved which have been carried out in recent years (Black et al, 2012, Prager and McKee, 2014, Valentine et al, 1981, Grealish et al, 2015, Omuto et al, 2013, Houšková et al, 2010, Panagos et al, 2012). However, these reviews have generally assumed that stakeholders have some knowledge of soils or are fully aware that they are using soils data and information. The aim of this study is to understand soils data and information stakeholders' needs across Europe from a non-expert perspective. 
Jones et al. (2005) reviewed soils resources and information use across Europe and determined that these are traditionally associated through the function of food and fibre production, with increasing applications to other issues such as climate change and water resource management (Blum, 2005; Grealish et al. 2015, Haines-Young, 2011). Soil maps, data and information are used in many sectors besides soil science, such as farming, hydrology, land degradation, policy and environmental modelling (Valentine et al. 1981, Mather, 1988, Houšková et al, 2010, Hallett et al, 2011, Omuto et al, 2013, Prager and McKee, 2014). The majority of soil information users indicated that key soil attributes are readily available (Wood and Auricht, 2011). However, improvements in a range of soil properties such as soil moisture, toxicity, biology and carbon are required (Auricht, 2004, Grealish et al. 2015).

Furthermore, engineering properties such as subsidence and corrosion are also of interest (Pritchard et al, 2015). These types of information are available but awareness of data accessibility and where to find them remains challenging. Information needs are also specific to stakeholder requirements and the spatial resolution of the undertaking. Black et al, (2012) consulted a wide range of stakeholders in developing the Soil Monitoring Action Plan for Scotland with further consultation taking place with farmers and local authorities by Prager and McKee, (2014). Key improvements mentioned were finer spatial resolution, soil trends, soil biological and physical indicators and sealing.

The FAO (2012) identify three major challenges in addressing soil information availability. The first of these focusses on the importance of soil protection, particularly to the global modelling community as it will help mitigate and adapt to issues such as climate change and food security. A second consideration is soil monitoring, focusing on improving global soil data at finer scale resolution. The third looks at advancing Digital Soil Mapping (DSM) and Digital Soil Assessment (DSA) techniques. DSM and DSA offers potential to map soil properties at detailed and broad scales (McBratney et al, 2003; Behrens and Scholten, 2006; Carré et al, 2007; Hartemink et al. 2008). However, it is not clear how any of these 
challenges reflect the needs of stakeholders, and difficulties remain around integrating the capability of models and the envisioned users of this data.

Stakeholder interaction and participation should be considered from the outset, and this is very rarely done (Reed, 2008). Studies by Bouma (2012) and Black et al. (2012) highlighted that end-users were often not aware that they were using soils data and information so could not easily communicate further needs. It is therefore not straightforward to assume what the needs of envisioned users of 'new' soil information are, in particular where this information is embedded in derived tools. Here we planned a survey of non-expert users to investigate their current needs and perceived gaps in their ability to deliver in their work activities. This information is vital in addressing how new soil tools and products, such as DSM and DSA, might (or might not) meet the stakeholder requirements and the likelihood of such products being of practical use. Our aim is therefore to investigate what soils assessments and tools stakeholders currently use and what improvements, if any are required for future soil products/information sets.

\section{Methodology}

A detailed questionnaire was carried out to consider the range of soils data and information currently being used across Europe with a focus on explicit and hidden soils information being used by non-expert stakeholders: non-experts being people who use soils information or data in their everyday work but who are not expected to be academically trained soil scientists.

The questionnaire was compiled using the web-based survey programme Qualtrics (http://www.qualtrics.com/). In addressing the different uses of soils data and information, we considered it important to address functions of soils and contact stakeholders with close connections in and around these functions. Therefore, stakeholders were identified in order to be representative of the primary functions of soils (http://www.fao.org/resources/infographics/infographics-details/en/c/284478/) including biomass production, cultural heritage, regulating, biodiversity/habitats and infrastructure. A 
list of organisations across Europe, with named soil contacts, was draw up by accessing published materials, on-line searches and personal knowledge. The remit and primary activities of these organisations corresponded well with at least one of the soil functions and provided coverage across the soil functions. Stakeholders were based around commercial organisations, learned societies, non-governmental organisations (NGOs), local authorities and government organisations. A total of 98 organisations were contacted across 22 countries in Europe. Of these, 34 organisations can be considered trans-European in their activities i.e. no specific alignment with any one region or country. A pilot study of the questionnaire was conducted with staff at The James Hutton Institute (Aberdeen) and the Scottish Government's ethics committee; the questionnaire incorporated amendments following relevant feedback. The survey was carried out from July to August 2015 and was made accessible to stakeholders through an anonymous online link.

\section{Questionnaire Results}

\subsection{What sectors use soils information?}

There were 310 individual responses to the questionnaire from 77 out of the 98 organisations we contacted and, from this, $93 \%$ of stakeholders said that they handled information about soil in their work.

Stakeholders were asked to identify what best describes the activities of their organisation. Stakeholders could tick more than one option for this question in order to obtain a broader understanding of activities associated with individual organisations. The top three activities were agriculture, research organisations (universities, institutes etc.) and conservation (Fig. 1). Stakeholders who ticked 'other' ranged from people who worked in landscape photography, archaeology and oil and gas services. This shows that there is a wide array of stakeholders who have an interest in soils data and information and who may use certain tools and assessments related to activities within their organisation. 


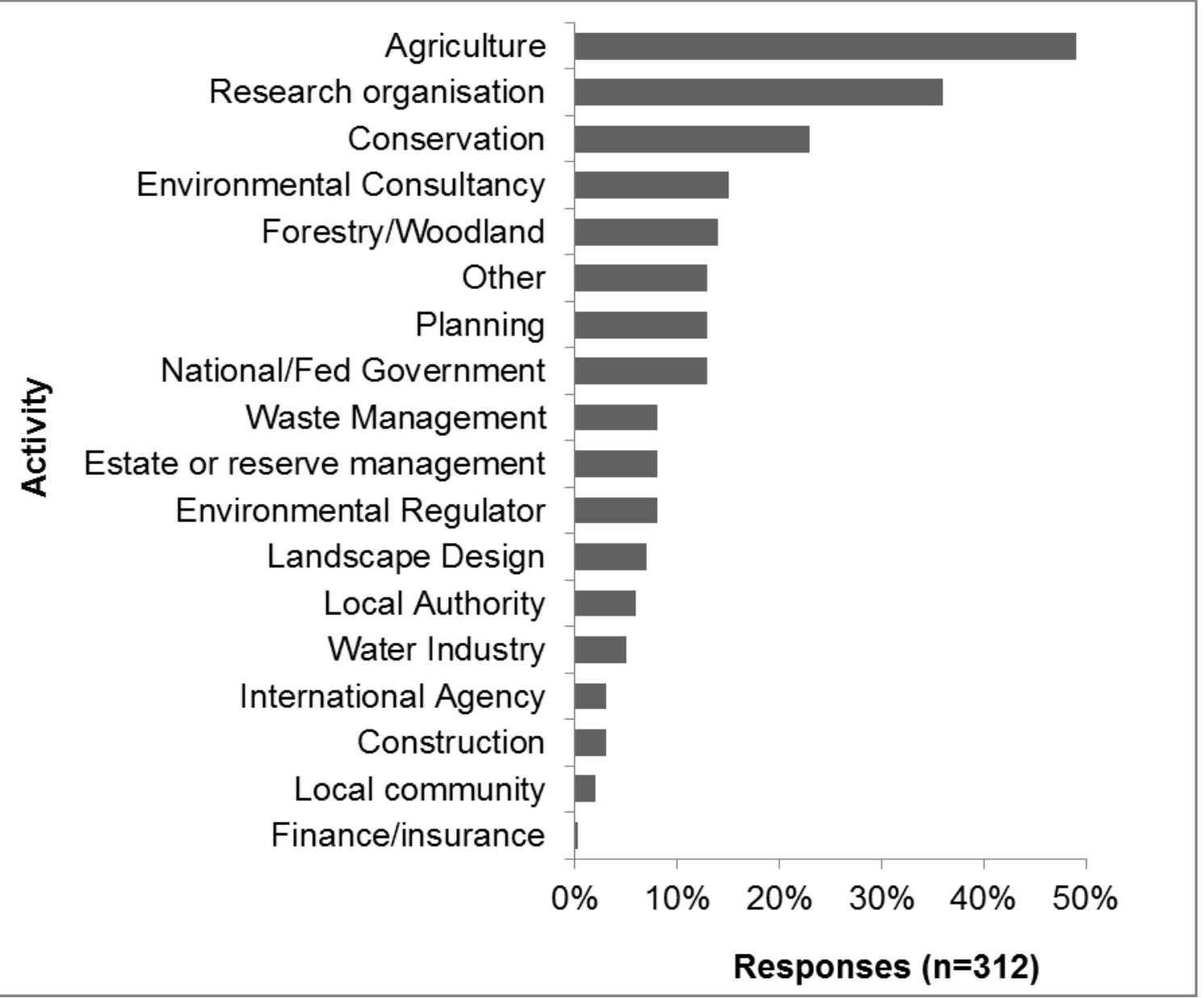

Fig.1: Range and type of organisations and the percentage of responses to the questionnaire.

This was to get an understanding as to the variety of organisations people worked for.

N.B. Stakeholders could tick more than one option for this question.

\subsection{Tools and assessments and awareness of embedded soils information}

Stakeholders were encouraged to tick as many boxes as possible in terms of what tools and assessments they use in their work. These assessments are grouped by related soil functions. Most responses came from people who were connected with agricultural production and conservation of habitats and biodiversity. Respondents were asked about how aware they were that many of the assessments had soils information embedded within them, with $87 \%$ saying that they were 'aware'. 
In relation to 'Biomass Production', it was found that the two main tools predominantly used were agricultural land evaluation and fertiliser/pesticide usage assessments. In terms of assessments grouped under 'Infrastructure', it is the extraction of raw materials such as clay, sand and silt, followed by assessment of the impacts of soils on assets such as pipes and electric cables. Nitrate Vulnerable Zones (NVZs) were found to be the main assessment tool used by stakeholders closely associated with 'Environmental Regulation' with soil erosion and diffuse pollution to water following closely behind.

Habitat suitability maps and land restoration assessments were the most commonly used assessments by stakeholders related to 'Habitats and Biodiversity'.

The number of stakeholders requesting information on fundamental soil properties from the questionnaire was relatively high. Soil chemistry (primary contaminants) and other properties including soil acidity, alkalinity and carbon had the highest demand and application (Fig.2). A number of other assessments which were not listed in the survey were also used by stakeholders including soil climate zones to identify nutrient demands of crops and grasslands. 


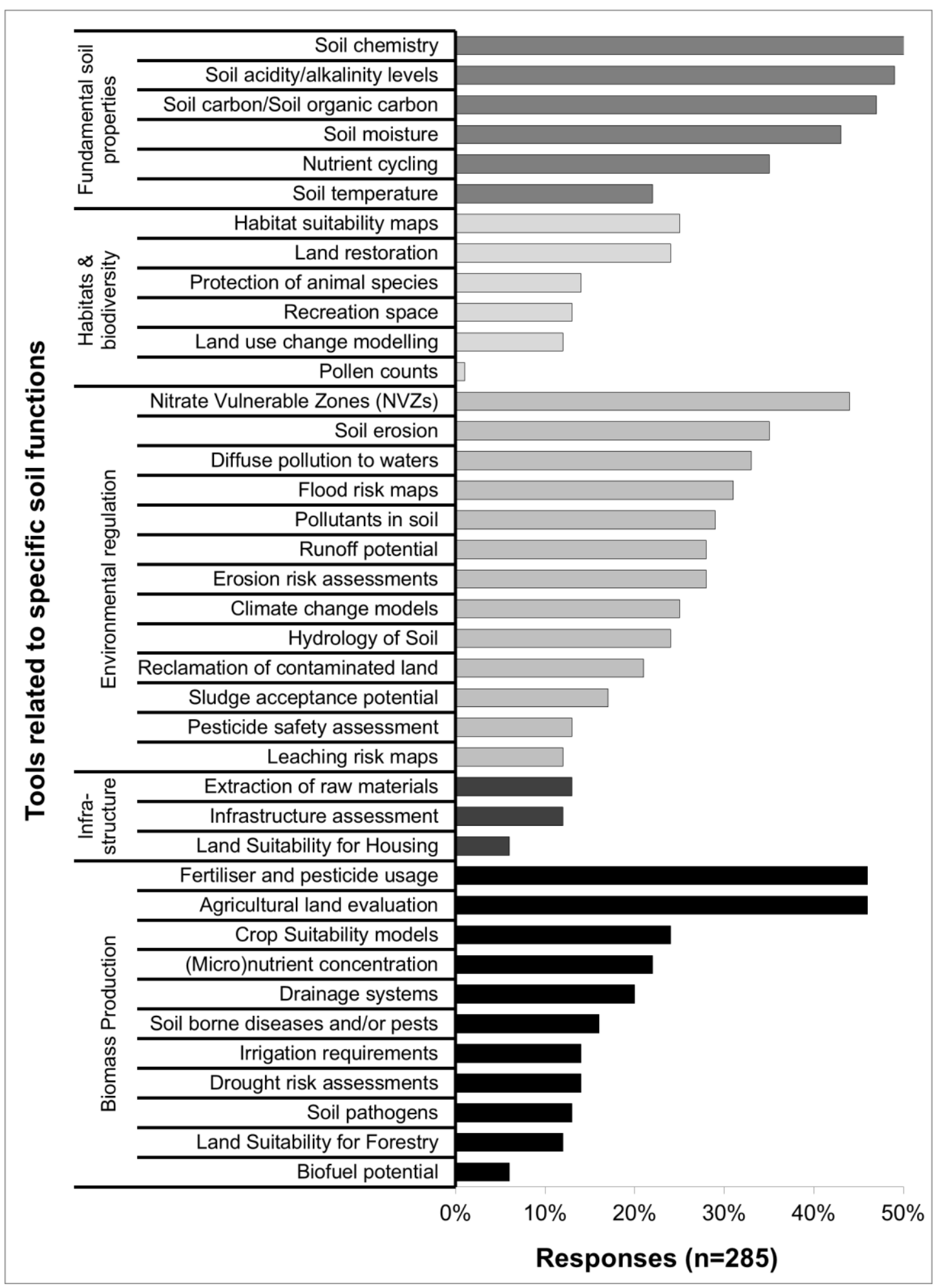

Fig.2. Tools and assessments used and percentages used by respondents.

These are broken up into their closest related soil function.

\subsection{Sources of information, licencing and spatial importance}


Respondents were asked to identify what sources they used to acquire soil information required for their work. The use of maps in either paper or digital format is the most prolific with $78 \%$ of respondents using them while $65 \%$ of respondents use Geographical Information Systems (GIS). Other sources consisted of social media websites and discussions with knowledge transfer exchange with stakeholders ( $11 \%$ of respondents). On the whole, most stakeholders found most sources that they used either 'very useful' or 'useful. 95\% found the use of maps, expert knowledge and field and laboratory analysis to be either 'useful' or 'very useful'. However, $11 \%$ reported that GIS systems were 'not very useful' or 'not useful' (Fig. 3). 


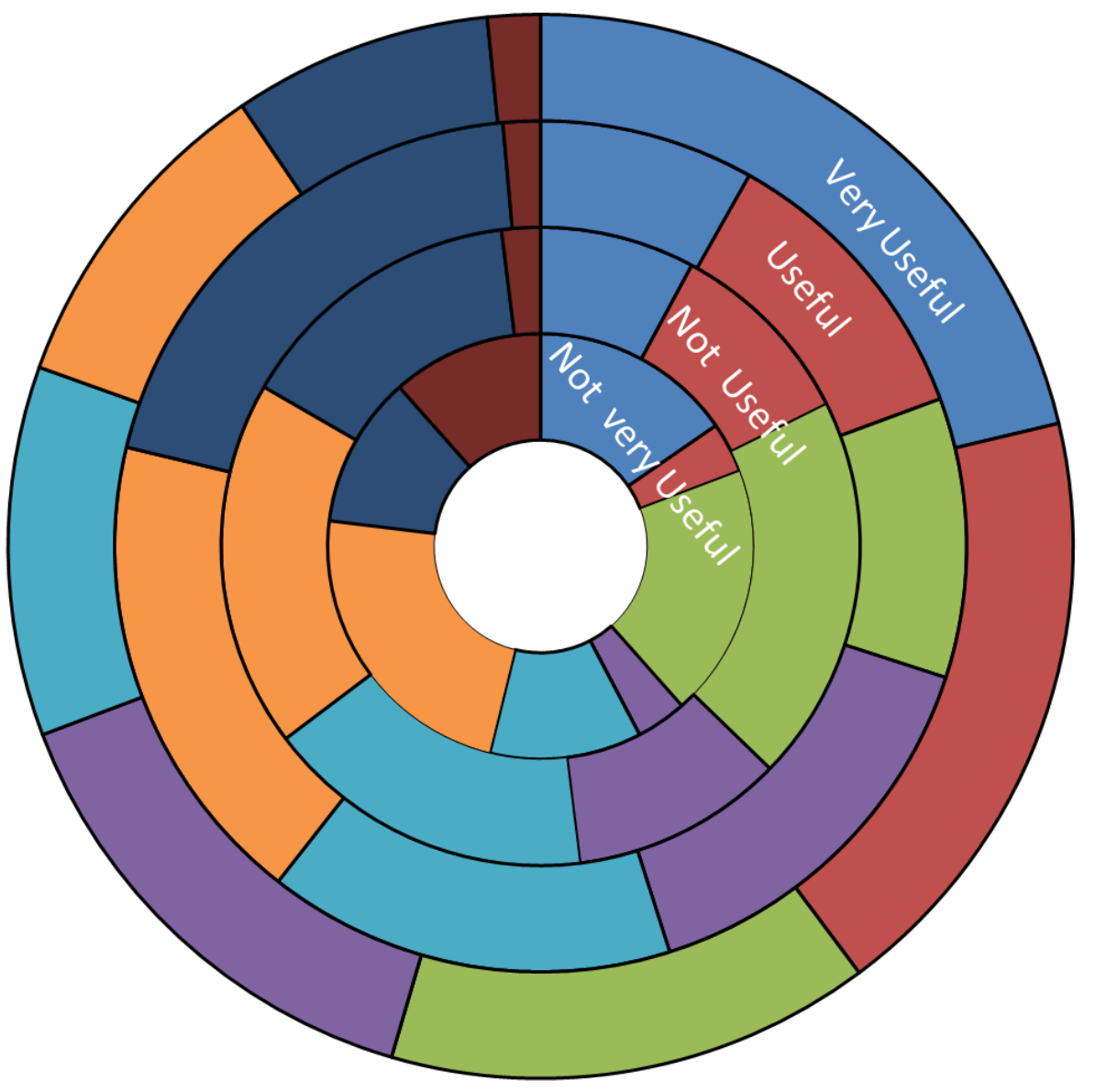

$\square$ Field analyses

$\square$ Expert Knowledge

$\square$ Geographical Information Systems (GIS) $\square$ Maps (paper or digital)

$\square$ Databases

$\square$ Books/reports

$\square$ Websites

$\square$ Other (please specify)

Fig. 3: How stakeholders rated usefulness of sources.

Outer circle represents the percentage of stakeholders who rated 'very useful.

Inner circle represents those who rated 'not very useful'.

When asked whether or not their organisation paid for licenced use of soils information, $49 \%$ said that their organisation did, $30 \%$ said 'no' and $21 \%$ said that they 'didn't know'. 
Respondents were asked to assess the importance of spatial soils information for wider applications and end-user groups and as a result of this, an overwhelming $98 \%$ of the respondents said that this was 'very important' or 'important'. Previously, we saw that $93 \%$ handled information about soil as part of their work. This extra $5 \%$ illustrates that those respondents who do not use, or acknowledge soil as part of their work still see the importance of spatial soil information for wider applications and end-user groups.

\subsection{Requested improvements to soil information and data}

Improvements to soil data and information were a key issue addressed in this questionnaire. Respondents were asked what they would like to see improved in relation to the information they already use and this has been summarised in Fig.4. We grouped improvements postsurvey to ease interpretation under four main themes: 'Uncertainty', 'Scale and Coverage', 'Metadata' and 'Fundamental Data'. Most stakeholders wanted soil information at a much finer resolution or scale to what they currently use. With regards to 'Uncertainty', respondents wanted improved accuracy and credibility of data sources. With regards to 'Scale and Coverage', as well as wanting information at finer scale resolution, respondents wanted to see improvements in co-ordinates of geographical locations (i.e. data in a format which they can georeference). With respect to 'Metadata' issues, respondents requested improvements in the availability of associated documentation related to the data. Finally, under the category of 'Fundamental Data', we see that respondents wish to see improvements with trends over time and contemporary data. Respondents were then asked specifically if they would be interested in using any new information that might arise from improvements in spatial resolution/scale and uncertainty. From Table 1, we can see that there is a positive response to improvements regarding both of these issues. Other notable requirements ranged from improving map and data interpretations, and the ability to use multiple datasets or assessments. 


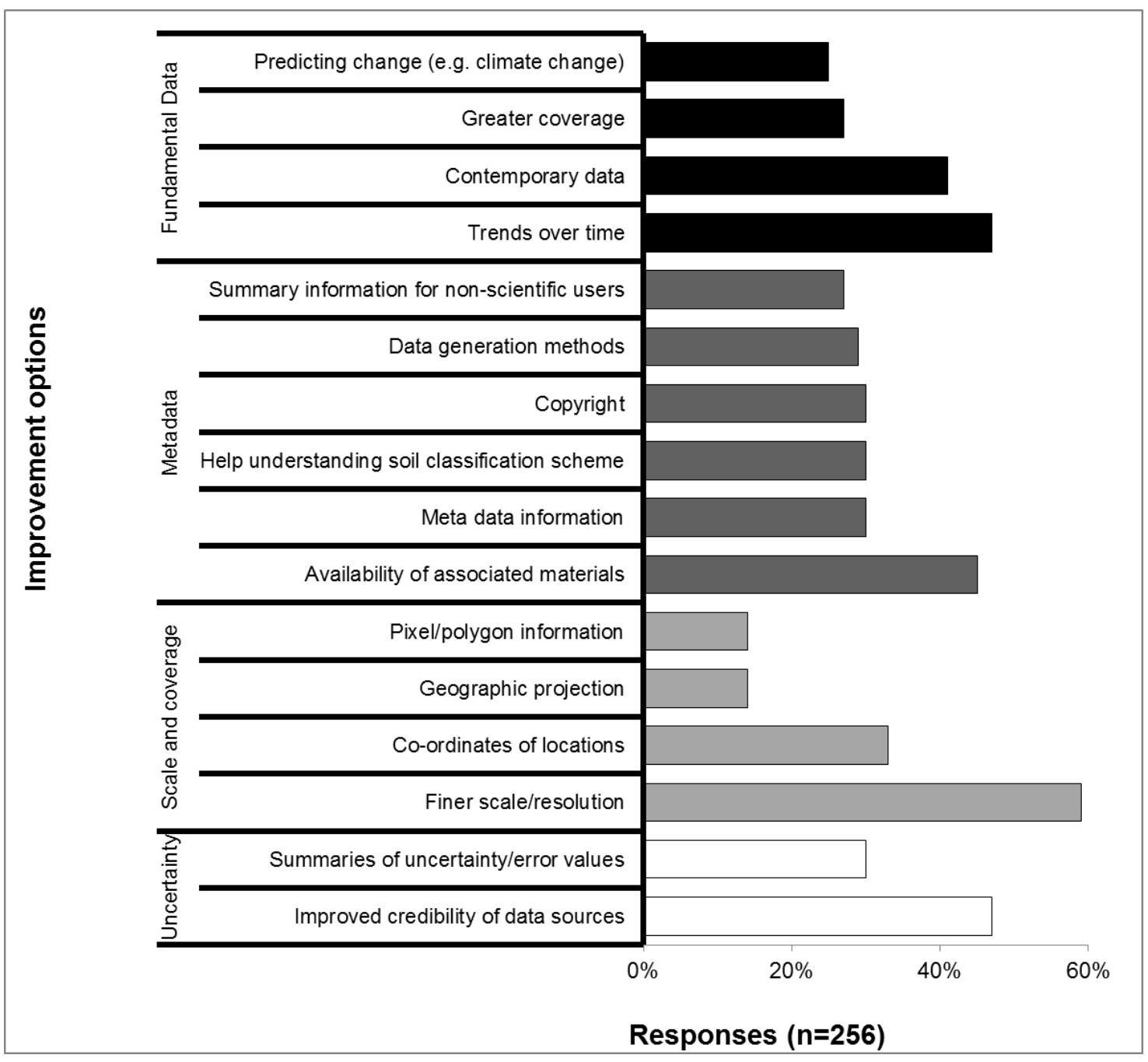

Fig. 4: Improvement recommendations by the stakeholders

\begin{tabular}{llll}
\hline$\underline{\text { Issue }}$ & Yes & No & $\frac{\text { Total }}{\text { responses }}$ \\
$\begin{array}{l}\text { Spatial } \\
\text { resolution/scale }\end{array}$ & 209 & 36 & 245 \\
$\begin{array}{l}\text { Summary of } \\
\text { uncertainty/error }\end{array}$ & 159 & 57 & 216 \\
$\begin{array}{l}\text { values } \\
\begin{array}{l}\text { Other (please } \\
\text { specify) }\end{array}\end{array}$ & 10 & 7 & 17 \\
\hline
\end{tabular}

Table 1: Would you be interesting in any new information arising from an improvement in spatial resolution/scale or summary of uncertainty/error values 
There was a space at the end of the questionnaire for respondents to add any extra information that might be useful. The main themes that came out from the additional responses were opportunities to increase knowledge transfer between research and policy makers and also the importance of education and training, which are vital in terms of increasing soil understanding.

\subsection{Relationships between organisations and desired improvements}

One of the main objectives of this study was to establish from the questionnaire what desired improvements were linked to the activities of particular activities. To achieve this, responses were cross tabulations between activities of the organisations and the desired improvements the stakeholders had requested. This was undertaken using the Qualtrics software. The cross tabulations were then used to create heat maps using $\mathrm{R}$ Statistics software (https://www.r-bloggers.com/citing-r-or-sas/) (Fig. 5). The legend indicates how the shading relates to the number of people who answered responses to both of these questions i.e. the darker the colour then the greater the correspondence between activities within that specific organisation and the requested improvements. From this we can see, improvements in finer/scale resolution are being requested most by stakeholders whose activities revolve around agriculture or research but consistently needed across all organisational activity groups. Trends over time are also particularly related to those working in agriculture and research but also sought by stakeholders in conservation and national/federal or governmental agencies. 


\section{Organisational Activities}
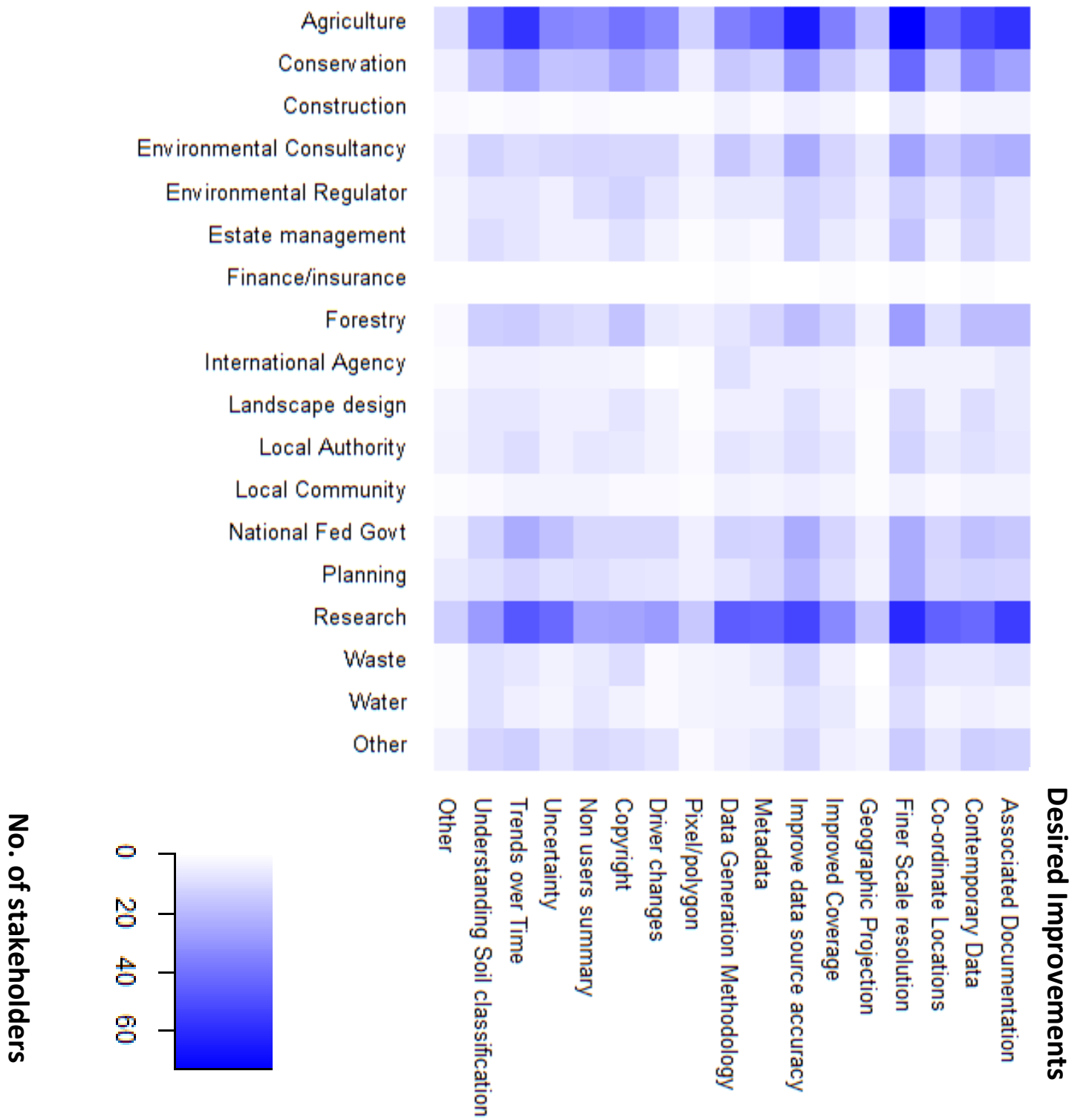

Fig. 5: Heat map showing the cross tabulation of responses $(N)$ between the activities of an organisation and suggested improvements in soil related information.

The darker the colour indicates a greater number of responses.

Using the same data, we converted the crosstabs into percentages to explore needs within activity groups. For the majority of organisations (Fig. 6), finer scale resolution and, associated, improved data accuracy predominated individual organisational user needs. Some organisations identified quite specific needs. In the finance/insurance category, these include improvements in contemporary data, finer scale resolution, improved coverage and 
methodology in how the data was generated. In the water sector, understanding soil classification and non-(expert) user summaries were identified as relatively high needs.

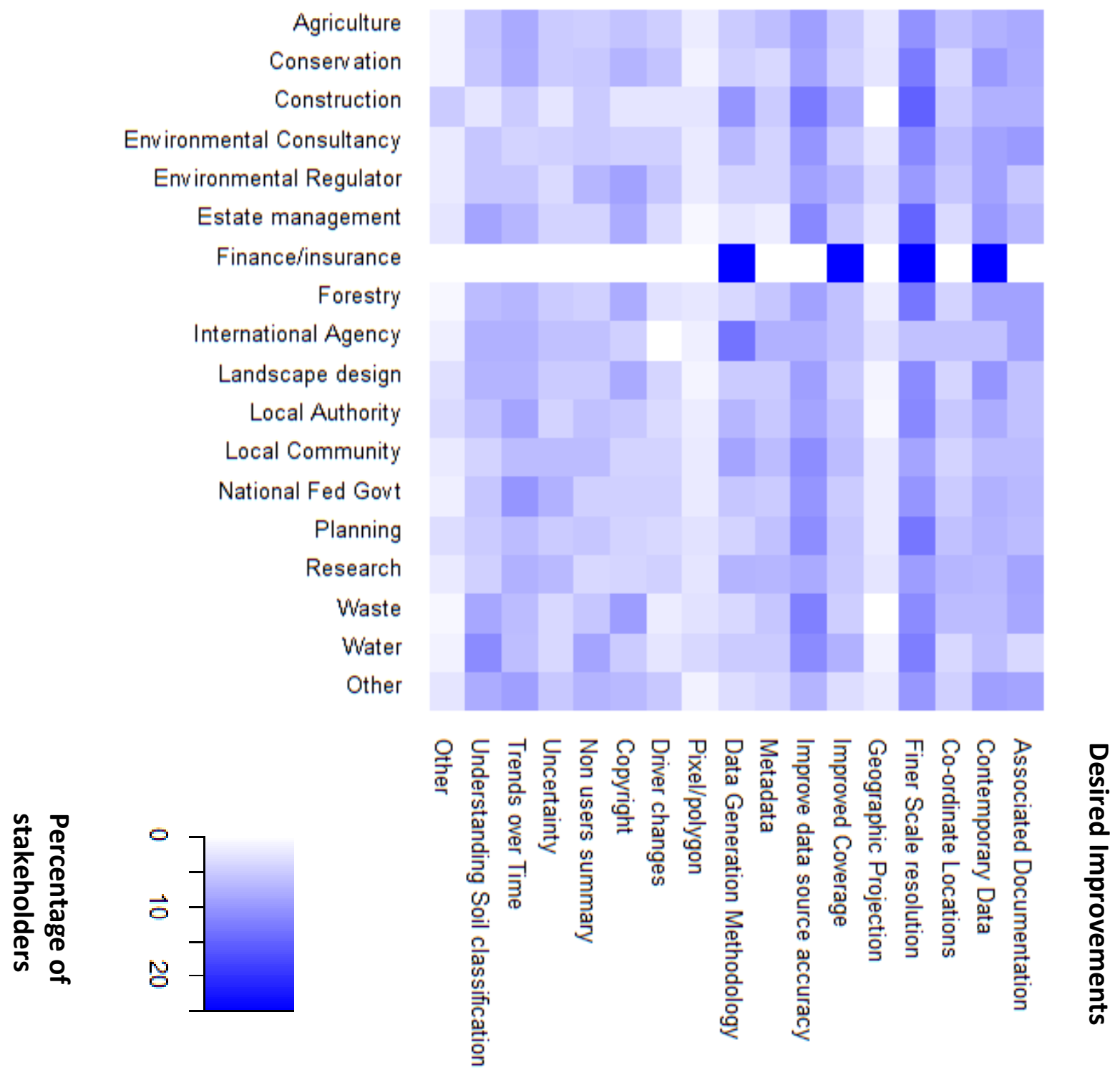

Fig. 6: Heat map showing the cross tabulation of responses (\%) between the activities of an organisation and suggested improvements in soil related information. The darker the colour indicates a greater percentage of responses by each organisation. 


\section{Discussion}

It is encouraging that we were able to obtain a large number of responses from non-expert stakeholders across substantially different organisations. It is clear that many diverse sectors are using, wish to use or access soils information on a regular basis to support day-to-day work practices. Moreover, our survey demonstrates that soils data and information are widely used in a range tools and assessments and are often integrated with other data sources such as historical data on climate and vegetation (e.g. where soil climate zones were used to establish nutrient demand for crops and grassland for regional animal manure management).

The survey responses also identified that there are barriers to accessing and using appropriate soil data. Overall, it would seem that stakeholders find difficulties obtaining and collecting information for projects which are under licence or where they have to pay for the use of it. Payment for use of data is particularly dependent on organisations procurement procedures and that different organisations are willing to pay varying amounts in order to obtain certain data for their work or projects (Montanarella and Vargas, 2012; Diafas et al. 2013). It is unclear how much this constituents a significant barrier to the use of soil information, as payment was not identified as one of the key improvements from the questionnaire. However, improving accessibility would clearly benefit non-experts. Alongside this, there is a clear need to address technical understanding with needs identified for knowledge transfer between research and policy, education and training, improving associated supporting information, understanding soil classifications and non-expert user information. A need for more technical knowledge may well reflect a lack of soils in school and university level education. The level of responses suggests that there is demand (and opportunity) for soils training opportunities focussed on non-experts and practical applications. In parallel, there is also a clear need for increased skill capacity in GIS within organisations using spatial soil data and information. Without this, it is difficult to see how 
new spatial soil products, which are predominately GIS in nature, can be widely adopted for practical use.

Stakeholders used a variety of information sources and of these, it was notable that a high proportion of people found GIS to be the least useful source of information even though a high proportion of stakeholders use or want to use spatial information and that GIS is a widely used spatial information platform. This may be due to constraints around technical ability, accessibility to GIS software (although open-source GIS software is available e.g. QGIS), or could allude to a more fundamental problem with the GIS medium being inadequate for the assessments undertaken by the respondents.

Other sources of information that were mentioned ranged from the use of social media sites like Twitter, academic journal articles and discussions with other stakeholders. Although not used widely at present, social media does now present real and widespread opportunities to communicate with and inform non-experts. Interestingly, most people found field and laboratory analyses to be 'very useful' or 'useful alongside maps, whether in paper or digital format, and expert knowledge. Reasons could be that stakeholders are utilising 'tacit knowledge' from field experts who acquired this information in the first place, thus using it as a validation tool (Hudson, 1992) and they are sufficient familiar with handling field and lab results. This may also reflect issues discussed about constraints with technical understanding and GIS skills limiting use of other soil data and information sources. The questionnaire also indicated widespread requirements for information on future scenarios and trends over time. There is a significant amount of legacy soils data available but much of this is at over 30 years old which could be used more to explore future scenarios and trends over time. There is however an underlying requirement for new information on soils to be able to determine current trends in soil properties and functions and to support modelling of future scenarios based on current conditions. Legacy data, on its own, cannot meet current user needs. 
Our survey indicates that a number of soil properties including texture (sand, clay and silt), contaminants, bulk density, $\mathrm{pH}$ and carbon have widespread use. These should be a priority in making more accessible and useable by addressing the needs for non-expert supporting materials, finer spatial resolution, trends over time etc. However, there are also other soil properties to be considered. Many of the answers in the questionnaire reflect instances where soil properties underpin soil functional assessments and tools. In such instances, the relevance of individual soil properties is "hidden" to the user and therefore the need for information on individual soil properties may not be fully expressed. This is a potential pit-fall to be recognised in any future assessments of stakeholder needs. Table 2 illustrates the soil properties used to derive these assessments using information gathered from previous documentation and literature (e.g. GlobalSoilMap, 2011a, GlobalSoilMap, 2011b, Mayr et al. 2006). This can be used in post-hoc identification of "hidden" soil properties in questionnaires, in particular when exploring needs for soil functional assessments and in ensuring that all necessary soil properties are being considered in the improvement of existing mapping or development of new modelling and mapping, such as DSM and DSA (c.f. Mayr et al. (2006). Expressing the links between soil properties and soil functions can also be used as a tool in raising stakeholders' awareness of the wider range of soil properties which underpin the soil functional assessments and tools that they use regularly. 


\begin{tabular}{|c|c|c|c|c|c|c|c|c|c|c|c|}
\hline $\begin{array}{l}\text { Related Soil } \\
\text { Function }\end{array}$ & Assessments & $\begin{array}{l}\text { Organic } \\
\text { carbon }\end{array}$ & $\mathrm{pH}$ & Clay & Silt & Sand & $\begin{array}{l}\text { Coarse } \\
\text { Fragments }\end{array}$ & ECEC & $\begin{array}{l}\text { Bulk } \\
\text { density } \\
\text { (whole soil) }\end{array}$ & $\begin{array}{l}\text { Available } \\
\text { Water } \\
\text { capacity }\end{array}$ & $\begin{array}{l}\text { Bulk } \\
\text { Density } \\
\text { (fine } \\
\text { earth) }\end{array}$ \\
\hline \multirow[t]{11}{*}{ Biomass Production } & Agricultural land evaluation & & & $\checkmark$ & $\boldsymbol{v}$ & $\checkmark$ & $\checkmark$ & & $\boldsymbol{v}$ & $\checkmark$ & $\boldsymbol{v}$ \\
\hline & Biofuel potential & & $\checkmark$ & & & & & & & $\checkmark$ & \\
\hline & Crop Suitability models & & & & & & & & $\boldsymbol{v}$ & $\checkmark$ & $\boldsymbol{v}$ \\
\hline & Drainage systems & & $\checkmark$ & & & & & & & $\boldsymbol{v}$ & \\
\hline & Fertiliser and pesticide usage & $\checkmark$ & $\checkmark$ & $\checkmark$ & $\checkmark$ & $\checkmark$ & $\checkmark$ & $\checkmark$ & & $\checkmark$ & \\
\hline & Irrigation requirements & & $\checkmark$ & & & & & & & $\boldsymbol{v}$ & \\
\hline & Land Suitability for Forestry & & $\checkmark$ & $\boldsymbol{v}$ & $\boldsymbol{v}$ & $\boldsymbol{\nu}$ & $\checkmark$ & & & & \\
\hline & (Micro) nutrient concentration & & $\checkmark$ & & & & & & & & \\
\hline & $\begin{array}{l}\text { Soil borne diseases and/or } \\
\text { pests }\end{array}$ & & & & & & & & & & \\
\hline & Soil pathogens & & & & & & & & & & \\
\hline & Drought risk assessments & & $\checkmark$ & & & & & & & $\checkmark$ & \\
\hline \multirow{5}{*}{$\begin{array}{l}\text { Environmental } \\
\text { Regulation }\end{array}$} & Climate change models & $\boldsymbol{v}$ & $\checkmark$ & & & & & & $\checkmark$ & $\checkmark$ & $\boldsymbol{v}$ \\
\hline & Erosion risk assessments & $\checkmark$ & & $\checkmark$ & $\boldsymbol{v}$ & $\checkmark$ & $\checkmark$ & & & $\checkmark$ & \\
\hline & Flood risk maps & & $\checkmark$ & $\checkmark$ & $\boldsymbol{v}$ & $\checkmark$ & $\checkmark$ & & & $\checkmark$ & \\
\hline & Hydrology of Soil & & & $\checkmark$ & $\checkmark$ & $\checkmark$ & $\checkmark$ & & & $\checkmark$ & \\
\hline & Leaching risk maps & & $\checkmark$ & & & & & $\boldsymbol{v}$ & & & \\
\hline
\end{tabular}


Nutrient Vulnerable Zones

Pesticide safety assessment

Pollutants in soil

Reclamation of contaminated

Runoff potential

Sludge acceptance potential

Soil erosion

Diffuse pollution to waters

Fundamental Soil

Properties

Nutrient cycling

Soil acidity/alkalinity levels

Soil carbon/organic carbon

Soil chemistry

Soil moisture

Soil temperature

Habitat suitability maps

Land reclamation/restoration

Land use change modelling

Pollen counts

Protection of animal species

Recreational space 
Infrastructure assessment

Land Suitability for Housing

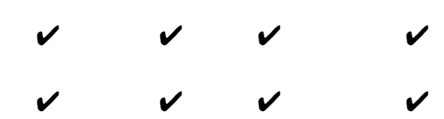

Table 2: Soil assessments mentioned in the questionnaire measured against probable soil properties that will be mapped as future work. Table adapted from: GlobalSoilMap (2011a, 2011b) and Mayr et al. (2006) 
1 Most stakeholders stated, from the questionnaire, that they require information at finer

2 spatial scale/ resolution than what is currently being offered. An obvious focus for future work is to deliver finer spatial scale in the key soil properties identified by the stakeholders (i.e. bulk density, soil contaminants, $\mathrm{pH}$, texture and carbon). However, one assumption is that finer spatial scale will lead to improved data and subsequent assessments. This may not be the case since scale is a complex parameter which is dependent on context and application (Goodchild, 1997, Wu and Li, 2009). Supported and promoted by FAO (http://www.fao.org/global-soil-partnership/pillars-action/4-information-and-data/en/), DSM is a major opportunity to gain soil property information at finer spatial scale than existing products, with the benefit of characterising accuracy and precision properties (Cavazzi et al, 2013). Such predicted soil property products can then be used to make significant advances in modelling and mapping the soil functional assessments which are widely used by diverse stakeholders and organisations. However, it is imperative that such approaches are matched with field assessments to critically evaluate and validate the accuracy of predicting soil properties at finer spatial resolution using existing (generally legacy) data.

\section{Conclusions}

The questionnaire was designed to understand how soils data and information are being used by non-expert stakeholders for a range of purposes. The responses indicate that stakeholders are generally aware of the utility of soil data and soil functional assessments for their work however they may not be aware of the full range of soil properties underlying soil functional assessments. Stakeholders identified that better and wider use of existing (and future) soil information by non-experts could be enabled by improvements in data access and user-friendly supporting materials. The majority of stakeholders require finer spatial resolution than is currently offered, contemporary information on soils and trends over time for soil functions as well as properties. Established soil modelling such as the global initiatives in DSM and DSA can address some of these needs. However, a clear message from stakeholders is that existing legacy soils data needs to be supplemented by new up-to- 
date soil data which is fit for current and future uses. Requirements for contemporary data demand investments in new and novel monitoring and sampling at sufficient spatial resolution and frequency to enable assessments of the range of soil functions. These will, in turn, be used deliver and shape a wide range of multi-organisational activities and policies. A question still remains on long we can rely on legacy soil data to make decisions today and into the future?

\section{Acknowledgements}

Thanks to all questionnaire participants who made this paper possible. Furthermore, the authors acknowledge Katrin Prager and Altea Lorenzo-Arribas at the James Hutton Institute for providing thoughts on questionnaire construction and how best to illustrate the results; Scottish Government who gave ethic approval to the questionnaire's use in Scotland; Oliver Pritchard for reviewing and suggesting improvements to the manuscript; Fiona Fraser for providing guidance on how to illustrate the cross-tabulation analysis using heat maps; the Rural and Environment Science and Analytical Services Division of the Scottish Government (RESAS) for funding support to Allan Lilly and Helaina Black and the sponsors EPSRC and Macaulay Development Trust for funding this $\mathrm{PhD}$ research; the reviewers for comments on a previous version of the paper.

\section{References}

Auricht, C. 2004. Natural Resources Atlas and Data Library - User Review. National Land and Water Resources Audit. Accessed from http://lwa.gov.au/products/er040794 [Last Accessed 20th July 2017]

Behrens, T., Scholten, T, 2006. Digital soil mapping in Germany-a review. J. Plant Nutr. Soil Sci., 169, pp.434-443.

Bibby, J. et al., 1982. Land Capability Classification for Agriculture. The Macaulay Land Use Research Institute, Aberdeen. ISBN 0708405088 
Black, H. et al., 2012. Soil Monitoring Action Plan. Accessed from

54 (http://www.environment.scotland.gov.uk//media/59999/Soil Monitoring Action Plan.PDF)

$55 \quad\left[\right.$ Last accessed $13^{\text {th }}$ December 2016]

56 Blum, W.E.H, 2005. Functions of soil for society and the environment. Reviews in

57 Environmental Sci and Bio/Technology, 4, pp.75-79.

58 Bouma, W. et al. 2012. Soil information in support of policy making and awareness raising.

59 Curr Opin in Environmental Sustainability 4, 5: pp.552-558.

60 Britz, W. and Witzke, W. 2014. CAPRI model documentation. [Accessed from

61 http://www.capri-model.org/docs/capri documentation.pdf [Last accessed 21st July 2017]

62 Carré, F. et al. 2007. Digital soil assessments: Beyond DSM. Geoderma 142, pp.69-79.

63 Costanza R, d'Arge R, de Groot R, Farber S, Grasson M, Hannon B, Limburg K, Naeem S,

64 O'Neill R.V, Paruelo J, Raskin RG, Sutton P, van den Belt M. The value of world's service 65 and natural capital. Nature 1997; 387:253-60.

66 Diafas, I. et al. 2013. Willingness to Pay for Soil Information Derived by Digital Maps: A

67 Choice Experiment Approach. Vadose Zone Journal Vol.12, No.4, DOI:

$68 \quad 10.2136 / v z j 2012.0198$

69 Environment Agency, 2009. Groundwater protection: Principles and Practice (GP3) (August 702013 Version 1.1.) [Available at:

71 https://www.gov.uk/government/uploads/system/uploads/attachment data/file/297347/LIT 7

$72 \quad 660 \quad 9 a 3742 . p d f]\left[\right.$ Last accessed $26^{\text {th }}$ September 2015]

73 FAO. 2012. Towards Global Soil Information: Activities within the Geo Task Global Soil Data:

74 Workshop report. Accessed from

75 http://www.fao.org/fileadmin/templates/GSP/downloads/GSP Soillnformation WorkshopRep

76 ort.pdf [Last accessed $10^{\text {th }}$ September 2015] 
77 GlobalSoilMap, 2011a. GlobalSoilMap.net: New Digital Soil Map of the world. [Accessed

78 from https://www.google.co.uk/search?q=globalsoilmap.net\&ie=utf-8\&oe=utf-

79 8\&aq=t\&rls=org.mozilla:en-GB:official\&client=firefox-

a\&channel=sb\&gfe $\quad r d=c r \& e i=a R 3 j V L W p O o S V 8 w O K 4 Y H w B Q] ~\left[L a s t ~ a c c e s s e d ~ 17^{\text {th }}\right.$ February 2015]

82 GlobalSoilMap, 2011b. Specifications Version 1: GlobalSoilMap.net products: Release 2.1.

83 Technical report

84 Goodchild, M.F., 1997. Towards a geography of geographic information in a digital world.

85 Computers, Environment and Urban Systems 21, 377-391

86 Goodchild, M.F., Quattrochi, D.A., 1997. Scale in Remote Sensing and GIS. Lewis

87 Publishers, 1-11

88 Grealish, G.J. et al. 2015. Soil survey data rescued by means of user friendly soil

89 identification keys and toposequence models to deliver soil information for improved land

90 management. GeoResJ. 6, pp. 81-91

91 Grunwald, S., Thompson, J.A., Boettinger, J.L., 2011. Digital soil mapping and

92 modelling at continental scales: Finding solutions for global issues. Soil Science

93 Society of America Journal 75, 1201-1213

94 Harter, T. and Walker, L.G. 2001. Assessing the vulnerability of groundwater. [Accessed

95 from www.dhs.ca.gov/ps/ddwem/dwsap/DWSAPindex.htm] [Last Accessed $20^{\text {th }}$ July 2017]

96 Houšková, B. et al, 2010. Assessment and strategic development of INSPIRE compliant

97 Geodata-Services for European Soil Data.

98 Hudson, H.D. 1992. Division S-5 - Soil Genesis, Morphology and Classification: The Soil

99 Survey as Paradigm-based Science, Soil. Sci. Soc. Am. J., 56, pp.836-841.

100 Mather, A.S. 1988. New private forests in Scotland: characteristics and contrasts. Area, 20,

$101 \quad 2$, pp.135-143 
102 Mayr, T. et al. 2006. Novel methods for spatial prediction of soil functions within landscapes 103 (SP0531). DEFRA, 26pp

104 McBratney, A.B. et al. 2003. On digital soil mapping. Geoderma 117, 1, pp.3-52.

105 Montanarella, L. and Vargas, R. 2012. Global governance of soil resources as a necessary condition for sustainable development. Current Opinion in Environmental Sustainability, .4, pp. 1-6

108 Omuto, C. et al. 2013. State of the Art Report on Global and Regional Soil Information:

109 Where are we? Where to go? FAO Report.

110 Panagos, P. et al. 2012. European Soil Data Centre: response to European policy support 111 and public data requirements Land Use Policy, 29 (2), pp. 329-338.

112 Prager, K.; McKee, A., 2014. Use and awareness of soil data and information among local 113 authorities, farmers and estate managers. The James Hutton Institute Internal Report.

114 Pritchard O.G, Hallett S.H \& Farewell T.S (2015) Probabilistic soil moisture projections to assess Great Britain's future clay-related subsidence hazard, Climatic Change, 133 (4) 635650.

117 Reed, M. 2008. Stakeholder participation for environmental management: A Literature

118 Review. Biological Cons., 141, 10, pp.2417-2431

119 Smith, P. et al. 2015. Biogeochemical cycles and biodiversity as key drivers of ecosystem 120 services provided by soils. SOIL D., 2, 537-586

121 Valentine, K.W.G. et al. 1981. A questionnaire to users of soil maps in British Columbia:

122 Results and implications for design and content. Can. J. of Soil Sci., 61, pp.123-135

123 Wood, B. and Auricht, C. 2011. ASRIS / ACLEP User Needs Analysis. [Accessed from

124 http://www.clw.csiro.au/aclep/documents/ASRIS User Analysis.pdf ] [Last Accessed $20^{\text {th }}$ 125 July 2017]

126 Wu, H., Li, Z.L., 2009. Scale Issues in Remote Sensing: A Review on Analysis, 
127 Processing and Modelling. Sensors 9, 1768-1793 